\title{
The future of science policy and innovation studies: some challenges and the factors underlying them
}

\section{Ben R. Martin (Orcid: 0000-0002-5186-0903)}

Chapter prepared for W. Canzler, S, Kuhlmann and D. Simon (eds), Handbook of Science and Public Policy, Edward Elgar (forthcoming)

January 2018

\begin{abstract}
The field of science policy and innovation studies (SPIS) is now over half a century old. Although relatively well established, it is confronted with various major challenges, as the author has set out in previous papers. In this chapter, we examine what factors might be underlying those challenges. The aim is to understand those factors so that we are better positioned to tackle and eventually overcome these challenges to the field of SPIS.
\end{abstract}

Keywords: innovation studies; science policy; research challenges; path dependence; disciplinary sclerosis; hyper-competition; research integrity

\section{Introduction}

The field of science policy and innovation studies (SPIS), although now well established, faces a number of challenges. In previous papers (Martin, 2013 \& 2016b), I identified 15-20 major challenges for the field. This chapter, in contrast, sets out to analyse what factors might be underlying those challenges. Some of these factors are primarily specific to SPIS, others more generic to academic research. By understanding 
more clearly these factors, we may be better placed to tackle and ultimately to overcome the various challenges.

The structure of the chapter is as follows: section 2 examines the nature and characteristics of the field of science policy and innovation studies, and the reasons for focussing on it. Section 3 analyses underlying factors that are relatively specific to the field of SPIS, while section 4 examines more generic ones. ${ }^{1}$ In section 5 we consider the effects of these on the culture of the field and on the behaviour of SPIS researchers. Finally, section 6 summarises the main conclusions to emerge.

\section{Science policy and innovation studies}

SPIS $^{2}$ first began to emerge as a field around 60 years ago. It has grown from a handful of individual scholars in the late 1950 to several thousand today (Fagerberg and Verspagen, 2009). Over this time, the field has matured considerably, with the establishment of dedicated research centres and groups beginning in the second half of the 1960s in Europe ${ }^{3}$ and then spreading. As a result, SPIS now trains most of its own PhDs rather than importing them from other fields as it did in the early decades. From the 1970s, it began to create its own journals, several of which have subsequently

\footnotetext{
1 This distinction between 'specific' and 'generic' represents something of an oversimplification, but is nevertheless useful for analytical purposes here.

2 In the early years, the field was most commonly known as 'science policy' (or sometimes 'research policy’). Subsequently, 'technology’ was often added to the label and later 'innovation'. Today, the term 'innovation studies’ is most commonly used to describe the field (and associated policies - see Godin, this volume). However, the longer term 'Science Policy and Innovation Studies' (SPIS) is used here to reflect this evolutionary development. A full definition of the field and what is included and excluded can be found in Martin (2012, p.1220).

3 The Research Policy Institute (RPI) at Lund University and the Science Policy Research Unit (SPRU) at the University of Sussex were both set up in 1966.
} 
achieved high standing. Later, in the 1980s, with the development of evolutionary economics and the concept of national systems of innovation along with the resource-based view of the firm, it began to acquire some of the elements of what might be seen as a proto-paradigm (Martin, 2012). There is now an established career structure within SPIS for those who wish to pursue work in the area, with numerous posts (especially in business schools) and with top innovation scholars often being highly regarded in adjacent social sciences such as management and economics. In short, the field is beginning to exhibit certain disciplinary characteristics (Steinmueller, 2013; Martin, 2016b).

Yet SPIS remains far short of being an established discipline, and indeed may never become one. In particular, the field remains intrinsically interdisciplinary, not least because of the nature of the real-world problems it addresses. To tackle these problems requires drawing extensively upon a range of cognate social science disciplines including business and management, economics, organisational studies, economic geography, political science, sociology, and history (e.g. history of technology, business history). Likewise, although there has been a shift in the balance in recent years, the field remains more problem-driven than theory-driven and hence is more susceptible to changes in public policy.

Moreover, since the nature of SPIS is such that it will never attract large student numbers (most teaching inevitably focuses on the Masters and doctoral level, with a few optional courses for undergraduates studying science or engineering), it is inevitably heavily dependent on winning research project income, often short-term in nature. As such, it is particularly vulnerable to the competitive pressures now bearing down on the academic community. In addition, as we shall see in the following section, this 
dependence on external research income points to the importance of keeping up with a rapidly changing world and the evolving needs of 'users' (policy-makers in government and decision-makers in other organisations concerned with science, technology and innovation).

Thus, SPIS shares certain characteristics with much of the work carried out in business and management schools. In particular, there is a high level of intellectual and institutional insecurity relative to more established 'policy sciences' like economics and political science, an insecurity that often manifests itself in the form of ritualistic imitation of what are seen as being more scientific research styles (Diesing, 1982/2005). ${ }^{4}$ Consequently, while the focus of this study is SPIS, some of the lessons we draw may be generalizable to other fields with similar characteristics, in particular much of the work in business and management studies.

\section{SPIS-specific factors}

\subsection{Path-dependence and lock-in vs. keeping up with a rapidly changing world}

Although SPIS has become well established as an academic research field over the last two decades, there is a danger that it is not keeping up sufficiently with a rapidly changing world and research environment. Many SPIS researchers understandably prefer to stick with the 'tried and tested', whether in terms of the objects of study, or conceptual frameworks and models, or methodological approaches and analytical techniques. As a result, there is often a tendency to focus on yesterday's problems, with a significant time-lag in adjusting to the new problems emerging with regard to policies

\footnotetext{
${ }^{4}$ I am indebted to Richard Whitley (private correspondence) for this point and drawing my attention to Diesing's book.
} 
for, and the management of, science, technology and innovation. Yet as a field heavily dependent on project funding, it is obviously vital to keep up with the changing needs of policy-makers.

As I have shown elsewhere (Martin, 2016b), analysis of the empirical focus of innovation papers reveals a continuing heavy emphasis on manufacturing, especially high-tech manufacturing, even though manufacturing now represents only a small proportion of economic activity in many advanced economies. Conversely, there is, with some exceptions, a relative neglect of innovation in non-manufacturing activities (in particular services - e.g. financial innovations), of non-technological innovations (organisational, social), and of innovations aimed at sustainability, protecting the environment and enhancing well-being rather than increasing productivity and wealth-creation. ${ }^{5}$ In addition there are some who would argue that technology and innovation have all too often brought increased risks and unintended consequences, which implies we need to move towards more 'responsible' innovation (e.g. Hellström, 2003; Owen and Goldberg, 2010; von Schomberg, 2011; Owen and Pansera, this volume; Williams, this volume). ${ }^{6}$ Linked to this is the growing inequality witnessed within countries over recent years and the role that innovations may have played in accentuating such inequality through 'winner take all' effects (Frank and Cook, 1995). ${ }^{7}$ Does not the SPIS community have a moral responsibility to say something about

\footnotetext{
5 See the discussion in Schot and Steinmueller (2016) on the need to move from 'Framing 2' of innovation policies (based around national systems of innovation) to 'Framing 3' aimed at 'transformative change’.

6 See also the related discussion in Maasen and Dickel (this volume) on the changing contract between science and society.

${ }^{7}$ While 'winner take all' effects are certainly not new, they do seem to have become decidedly more pronounced in recent years (Schilling, 2002; Autor et al., 2017).
} 
policies that might encourage innovations instead resulting in greater 'fairness for all' (Perez, 2013)?

Among the main challenges ${ }^{8}$ that such shifts in the external world bring for SPIS are moving:

- From innovation in manufacturing to innovation in services

- From innovation for productivity to innovation for sustainability ('green innovation')

- From innovation for economic growth to innovation for sustainable development

- From innovation for wealth creation to innovation for well-being

- From risky innovation to socially responsible innovation

- From innovations based on 'winner take all' to innovations generating 'fairness for all'

Although in recent years, there are some in the SPIS community who have begun to take up the above challenges, there are many others who remain in danger of 'fighting the last war'.

\footnotetext{
${ }^{8}$ For a more detailed analysis and discussion of these challenges, see Martin (2016). Linking them is the key point made by my SPRU colleague, Andrew Stirling, that innovation is not a process of following some ineluctable linear path but it has an element of directionality - in other words, "innovation is a vector, rather than just a scalar quantity” (Stirling, private correspondence). This is clearly linked with work by STS scholars on the social shaping or social construction of technology (e.g. Mackenzie and Wajcman, 1985; Bijker et al., 1987; Williams and Edge, 1996).
} 


\subsection{Cognitive imprinting in SPIS}

'Imprinting theory' suggest that institutions often reflect the culture and times when they were formed; their values, norms and ways of thinking tend to become imprinted and to live on (Stinchcombe, 1965; Martin, 2016b). With science policy and innovation studies now over 50 years old, it is perhaps not surprising that the way we conceptualise, define, measure and theorise innovation reflects the early years of the field in the 1960s and '70s, when manufacturing was all-important to economic development. This was a time when much innovation was heavily dependent on R\&D (including to a significant extent in-house research and technological development), and when innovative activities were relatively easily measurable in terms of such indicators as $R \& D$ funding and patents. The SPIS community consequently developed conceptual frameworks, models and theories based on such conceptions, definitions and measures of innovation as prevailed in those early decades. This is not to imply that innovations in services were completely ignored (see e.g. Barras, 1986 \& 1990) but there were certainly given far less attention by innovation scholars.

Now, however, there is a vast amount of innovative activity going on around the world that is not readily 'captured' by such definitions and measures - in particular, innovative activity that is incremental, not in the form of manufactured product innovations, involves little or no formal R\&D, and is not patented. This includes, for example, many process innovations (especially those in the factories of China and other emerging economies), financial innovations (such as derivatives ${ }^{9}$ - which played such a large part in bringing about the 2007-08 financial crisis), and organisational and social

\footnotetext{
${ }^{9}$ One of the few to warn of the risks of derivatives before the 2007-08 financial crisis was Tickell (2000).
} 
innovations. In short, much innovative activity today is currently not 'visible' with existing measures and approaches. Just as the great majority of the universe is not visible with existing telescopes but consists of 'dark matter' and the even more mysterious 'dark energy', so much innovative activity is currently largely invisible (NESTA, 2006 \& 2007) or what might be described as ‘dark innovation’ (Martin, 2016b). ${ }^{10}$ Hence, the challenge here is to move:

- From visible innovation to 'dark innovation'

\subsection{Gender imprinting ${ }^{11}$}

Many of the leading innovation scholars of today made their name in the previous decades when the emphasis was on high-tech manufacturing and on economic competition between the US, Europe and Japan. To develop their research reputation, individuals had to devote years of effort to studying a particular sector, technology or innovative product, building up their own (generally hand-crafted) databases on that chosen topic. At that stage, a large majority of researchers in their early to mid-careers were male. Inevitably they tended to focus on products or innovations that held a particular fascination to them such as cars, computers, cameras, TVs and mobile phones - i.e. what some might characterise as 'boys' toys'. These formed the empirical focus of many influential innovation papers.

There was far less interest in more mundane innovations, even those that over the last half century have had an immense impact on humanity. ${ }^{12}$ In particular, household goods

\footnotetext{
10 Marsili and Salter (2006) have previously written about 'The dark matter of innovation'.

11 While a gender-imbalance is certainly not specific to SPIS, it has had particular effects on the SPIS field, as this subsection shows.
} 
such as refrigerators and freezers, microwave ovens, washing machines and tumble driers, vacuum cleaners and numerous household cleaning agents have arguably done far more for $50 \%$ of the population of developed economies. These have enabled many women in developed economies to escape the drudgery of being a 'housewife', a task that in the mid-20 $0^{\text {th }}$ Century was at least as time-consuming as a full-time job (Gershuny and Robinson, 1988; Hartmann, 1981; Kan et al., 2011), rendering the pursuit of a career almost inconceivable to the great majority of married women at that time.

Hence the challenge for the next generation of IS researchers (one with a much improved gender balance extending into the higher echelons of the profession, one would hope) is to shift the balance of the empirical focus of SPIS research

\section{- From 'boy's toys' to often more mundane innovations that have done (or could potentially do) at least as much to improve the lot of humanity}

\subsection{Intellectual inbreeding}

In the early years of SPIS, most researchers migrated into the field from other disciplines (e.g. economics, management, sociology, organisational studies etc.) in which they had acquired their $\mathrm{PhD}$. This immigration gave the early field a rich cognitive diversity, whether with regard to the problems studied, the perspectives adopted, the methodological approaches adopted, or the theories and models developed. SPIS benefited immensely from this cultural melting-pot. As is apparent from intellectual history, the most radical or important research advances often come not

\footnotetext{
12 Prominent examples include the (intermodal) shipping container and marine diesel engines, two innovations that have contributed arguably more than any others to globalisation (in the case of the former, see Bernhofen et al., 2016) yet which have been almost entirely ignored by the SPIS community (the container is discussed briefly in Teece, forthcoming).
} 
from within the disciplinary mainstream but when researchers from two or more disciplines or fields come together, combine their efforts in new and creative ways, and produce some intellectual advance that would not have been conceivable if tackled solely by practitioners from a single field. Examples include advances in the early development of biochemistry, molecular biology, radio astronomy and more recently cognitive science.

In the late 1950s and early '60s, economists bumped into rural sociologists studying innovation. While there was initial suspicion or even hostility (Martin, 2012, p.1235), such encounters helped both sides better understand the nature of the innovation process. Later, they were joined by others - by management scholars, organisational researchers, political scientists and historians as well as former scientists and engineers - each bringing their own ideas, perspectives, methods and so on (Martin, 2012).

Now, however, because SPIS has its own dedicated centres and groups, most younger researchers have acquired their $\mathrm{PhD}$ within the field rather than from a neighbouring social science discipline. This undoubtedly offers certain advantages in that they have mastered a common body of literature and are well placed to build upon this efficiently. However, there is also a significant downside in the form of less diversity and variety. This brings with it the temptation to focus research efforts on 'safe' and consequently largely incremental work, with the danger that one may then end up knowing more and more about less and less.

The challenge here is:

\section{- Avoiding disciplinary sclerosis}




\subsection{Specialisation and diminishing returns}

With the development and acceptance of concepts, theories and 'stylised facts', and with the more professional training of young researchers, there are considerable pressures on academics (especially younger ones), starting from what is already well known, to go ever narrower and deeper. At the same time, because the key factors at work in the innovative activity under study are already reasonably well understood from previous studies, the tendency is to focus on factors accounting for an ever smaller part of the process or phenomenon under study. The findings are therefore often incremental, even sometimes rather trivial.

To a certain extent, this process of exhaustion of major research opportunities in a field is perhaps inevitable, at least if researchers stick to familiar issues and to tried and tested approaches. To overcome this, one may need fresh ideas from 'outsiders' (see subsection 3.4 above) as well as greater boldness by incumbent researchers prepared to take on new issues, to adopt new methods, to develop innovative conceptual frameworks - in other words, branching out rather than going narrower and deeper. Hence, the challenge here is:

\section{- Encouraging risk-taking and diversity}

\section{6 'Looking where the light is'}

As noted in subsection 3.3, it can take years of patient effort to develop databases on one’s chosen object of study (whether a sector, technology, product or innovation). Given the intense competitive pressures on academics today (see subsection 4.1 below) and the desire for quick results and publication, there is often a tendency to focus on objects or phenomena for which data already exist, and on variables that can be easily 
operationalised and measured. Hence the large number of empirical studies focusing on patents or on data from existing innovation surveys. Yet these do not necessarily provide appropriate measures for the most important factors at work, many of which may be less measurable or indeed not amenable to quantification at all (Nelson, 2016). In short, there is a danger of following the example of the drunk who has lost his keys and who is looking for them under the lamp-post not because that is where he thinks he dropped them but merely because "that is where the light is".

The challenge here is to encourage more researchers to engage in:

- Developing customised databases specific to the key factors at work (rather than re-using data that happen to be already available)

\section{More generic factors}

\subsection{Growing competitive pressures}

In the academic world, researchers face growing competitive pressures (especially in business schools - see Hall and Martin, 2017). There is competition to win research funds and to gain publication in top journals, for tenure and subsequent career advancement, for higher salaries (again particularly in business schools ${ }^{13}$ ) and income from consultancy, and above all for reputation and status. While none of this is new, those competitive pressures are much more intense than they were a few decades ago (Whitley, this volume).

\footnotetext{
13 In the US, seven of the top ten academic salaries (excluding those for university presidents) were for professors in business schools - see

http://www.thebestschools.org/blog/2013/11/25/10-highest-paid-college-professors-u-s/ (accessed on 29
} November 2017). 
While an element of competition is undoubtedly healthy for the scientific enterprise, extremely high levels of competition ('hyper-competition’) can bring various downsides (ibid.). Amongst other things, intense competition tends to accentuate fads and the hyping of particular ideas, a phenomenon again well known in business and management studies (Abrahamson, 1996; Huczynski, 1993). In the SPIS field and with the benefit of hindsight, it might be argued that during the 1980s rather too much emphasis was devoted to certain aspects of Japanese innovative activity (just-in-time, total quality, lean production), and in the 1990s to the hyping of new technologies such as IT and biotech. In the early $21^{\text {st }}$ Century, has too much attention perhaps been given to the innovative potential of SMEs, clusters or university-industry links, or to such concepts as open innovation or smart specialisation?

When competitive pressures are particularly pronounced, there is a danger of such fads being accentuated and of creating 'bubbles', as arguably seems to have happened in theoretical physics, where thousands have been devoting their attention to string theory with rather meagre results (Smolin, 2006), or in the case of the numerous social scientists who enthusiastically took up chaos and complexity theory in the 1990s. This points to the next challenge for SPIS, namely

\section{- Pricking academic bubbles and moving beyond today's 'fads'}

\subsection{Increasing emphasis on performance indicators}

As part of the effect of intense competitive pressures together with demands for greater public accountability, there has been growing emphasis on making research 'more efficient' - yielding more outputs, producing more 'excellent' research, creating more 'impact' on the economy or society. With this has come a proliferation of assessment 
mechanisms - at both individual and organisational levels (Simon and Knie, 2013) and associated performance indicators (Maasen and Dickel, this volume; Whitley, this volume). Those performance indicators are often linked to numbers of publications and citations. Publications (in particular, those in top journals - see next subsection) have achieved ever increasing prominence as the 'currency' of academics. They enable simple, standardised comparisons between individuals, especially for the academic job market (in particular in business schools). ${ }^{14}$

One inevitable consequence of this has been a proliferation of publications - a form of inflation of the academic currency with much greater expectations regarding expected publication output (e.g. for tenure or for a professorial chair) than 30 years ago. Another is a tendency to focus on certain types of research: on safe, low-risk research yielding incremental returns; on more ‘theoretical' research and more complex mathematical modelling; and on quantification and statistical or econometric sophistication, even if this comes at a cost of over-simplification or being removed from reality (see subsection 4.3 below).

This points to the challenge of

\section{- Breaking free from the tyranny of performance indicators}

\subsection{Pursuit of the 'top journals'}

The combination of fierce competitive pressures and the growing prevalence of assessment through performance indicators has resulted in an increasing premium being attached to publishing in the so-called 'top journals', with an ever-widening gap opening up between those leading journals and the rest in terms of recognition and

\footnotetext{
14 Paul Nightingale (private correspondence).
} 
standing. ${ }^{15}$ This is an illustration of a more general phenomenon in which increased competition and globalisation have resulted in a growing gap between 'the best' and the rest, another example being the effect of international league tables on the standing of universities.

Of those identified as ‘top’ journals, the great majority are situated in (and indeed largely define) the disciplinary mainstream. As a consequence, more heterodox research or interdisciplinary research (and the researcher working in such areas) is generally at a considerable disadvantage. Moreover, the top journals tend to emphasise theory, modelling, quantification and mathematical equations (Tourish, 2011). This may be appropriate for certain fields and for certain types of research. For others, however, where the phenomena under study are more complex and less well understood (i.e. most of social science), much research will be intrinsically exploratory with qualitative and open-ended approaches often being more appropriate (cf. Nelson, 2016). Yet this type of research is much more likely to be rejected by top journals as insufficiently theoretical, quantitative or 'rigorous'.

Attempts to adopt a more 'theoretical' approach in such cases is likely to result in the oversimplification of intrinsically complex phenomena (ignoring other factors that are difficult to operationalise or simply assuming 'all other things being equal'). This includes an emphasis on what can be readily quantified - i.e. variables that can be operationalised and for which data already exist (most likely in the form of some surrogate indicator providing a rather indirect measure of the variable one really wants to measure). Also often involved is an emphasis on technically very sophisticated

\footnotetext{
15 According to a study by Attema et al. (2014, p.495) on the value attached by researchers to being published in a top journal, economists “would sacrifice more than half a thumb for an AER publication”!
} 
statistics or econometrics. Indeed, statistical virtuosity is frequently assumed to equate to rigour and even depth. However, just as a violin virtuoso may be lauded for playing with great dexterity and precision, there may be other violinists who play with greater feeling and sensitivity who are ultimately judged to be greater musicians.

The consequence of this relentless pursuit of publication in top journals is a growing separation between what is publishable (at least in those top journals) and what is ultimately important and interesting. These days, contributions by economists in particular seem to be judged more on the mathematical elegance or statistical sophistication of their methods than on their relevance to addressing real economic challenges - in other words, they seem to have mistaken beauty for truth (Krugman, 2009; see also Romer, 2015, on the 'mathiness' of much economics). Of the ten most highly cited economics articles identified by Kim et al. (2006), no less than seven were econometric methodology (or statistical) papers. As Lawson (2009, p.760) caustically notes, the over-emphasis by neo-classical economists on mathematical deductivist models “mostly gets in the way of understanding”. Moreover, as Coase (2012, p.36) observes, "The degree to which economics is isolated from the ordinary business of life is extraordinary and unfortunate.” There are some suggestions that SPIS may have begun to move in a similar direction (Martin, 2016, p.446).

In addition, the increasing pressure on editors to raise the status of their journals and in particular their Journal Impact factor (JIF) has resulted in game-playing and even outright manipulation of JIF (for example, through such practices as coercive citation, inter-journal citation cartels, and holding accepted papers in an online queue for a year or more - see Martin, 2016a). As a result, the JIF metric can no longer claim to be a 
credible indicator of a journal's standing, often being more a measure of how adroitly the journal's editors have been manipulating their JIF through fair means or foul.

This points to the challenge set out in the 'Leiden manifesto' (Hicks et al., 2015) and in the San Francisco Declaration on Research Assessment (DORA) ${ }^{16}$ of

\section{- Rejecting the assumption that one can judge the importance of a publication} by the status of the journal in which it appeared

\subsection{Publication at all costs and the proliferation of journals}

Competitive pressures on researchers to publish at all costs along with commercial pressures on publishers to capture a growing share of this lucrative market have led to a proliferation of journals, many with very low standards for publication. This, together with concerns about the traditional business model of academic journals and the very considerable profits extracted by journal publishers, has contributed to the emergence over the last 15 years of open-access journals, shifting the burden of cost from readers and their institutional libraries to the researcher. ${ }^{17}$ Several of the early open-access journals in medicine and science have reasonable quality-control processes based on same form of peer review. However, many other journals have been set up by predatory publishers with little or no quality control procedures, their sole intent being to extract rent from authors desperate to publish and unable to gain publication in more reputable journals (Kolata, 2017). They offer the academic equivalent of vanity publishing for

\footnotetext{
16 See http://www.ascb.org/files/SFDeclarationFINAL.pdf (accessed on 2 November 2017).

17 Whether it is more equitable or morally better to charge the research author rather than the reader is not obvious. Certainly, such an argument is not normally applied in the case of novelists, music composers or artists, for example, even in cases where the latter receive some form of public subsidy.
} 
researchers intent on demonstrating to their superiors that they are 'research active' - i.e. capable of being published.

There has always been an implicit 'pecking order' for the academic journals in each field. For much of the $20^{\text {th }}$ Century, there were perhaps three distinct levels or 'divisions' of journals: the international leaders; respectable journals (e.g. national or more specialised ones); and what were widely perceived as lower quality journals. Now, however, open access has added two more levels or divisions beneath these: open-access journals with some limited pretence of quality control through peer review $^{18}$; and open-access journals willing to publish absolutely anything ${ }^{19}$, provided of course the author is willing to pay. Beall’s list (sadly no longer updated ${ }^{20}$ ) identified hundreds of predatory publishers and thousands of associated journals ${ }^{21}$. The result is that however ill-conceived the research and however poor the paper, researchers know that eventually they will be published, even if only in a bottom division journal.

\footnotetext{
18 Even where there is an element of peer review, there must be doubts about how effectively this works in practice - for example, a spoof article by Lindsay and Boyle (2017) on 'The conceptual penis' was favourably reviewed by two referees who recommended it be published in an open-access journal published by Taylor and Francis (see https://www.sott.net/article/351569-The-Conceptual-Penis-as-a-Social-Construct-Hoax-gender-studies-pa per-accepted-by-a-peer-reviewed-academic-journal - accessed on 29 November 2017).
}

19 For two examples of 'articles' accepted for publication by such predatory journals, examples that clearly demonstrate the complete absence of any quality control procedures whatsoever, see http://b.fastcompany.net/asset_files/-/2015/02/08/CocoaPuffsStudy2.pdf and http://www.scs.stanford.edu/ dm/home/papers/remove.pdf (both accessed on 29 November 2017).

20 However, the most recent lists can still be found at https://archive.fo/UK2ze (accessed on 29 November 2017). Responsibility for publishing such a 'blacklist' of predatory journals has now been taken over by Cabell’s International (see http://www.cabells.com/about-blacklist - accessed on 29 November 2017).

21 It would seem that the more extravagantly ambitious the scope of the title ("The Global Journal of Science, Social Science and Humanities”), the more likely the journal is to be predatory in character. 
Hence, the challenges are:

- Contributing to efforts to expose and exclude predatory publishers

- Establishing reputable open-access journals for the social sciences

\section{Effects on the culture and behaviour of SPIS researchers}

\subsection{Impact on culture}

Both the specific and generic factors described above are starting to have a significant effect on the culture of SPIS research and researchers. Historically, the prevailing culture and norms within SPIS have largely reflected the philosophy and values of the founding parents (Schein, 1983) of the field - individuals such as Chris Freeman, Richard Nelson and Nathan Rosenberg. Besides sharing a belief that the aim of research was not just to understand the world but also to change it, these pioneers were also characterised by openness and intellectual generosity, by an emphasis on helping younger researchers, by a willingness to serve the wider academic community (for example, devoting time and effort to infrastructure building such as setting up research centres and journals, and the provision of other 'public goods'), and by great integrity. For many years, SPIS has faithfully reflected the norms and values of its founders.

Now, however, that culture is under threat from some of the factors described above. Among the consequences are increasingly individualistic and proprietary behaviour among some researchers, who are more inclined to claim "it was my idea" and less willing to give others due credit or even to acknowledge their contribution at all. When Chris Freeman was asked about the origins of the notion of the national system of innovation (one of the most important conceptual advances in SPIS of the last 30 years), 
he gave the credit to Bengt-Åke Lundvall (Freeman, 1995, p.5), while Lundvall credited the concept to Freeman (Lundvall, 2004, p.531); whether that example would be followed today, say, by professors embedded in the intensely competitive environment of a business school is a moot point!

There are worrying signs that hyper-competition is encouraging researchers to become more aggressive or macho in their behaviour, almost certainly aggravating the existing problem of too few top women researchers in the field. For similar reasons, some researchers are becoming less collegial and civil. For instance, reviews of papers submitted to journals or presented at conferences are often couched in far more critical terms than 20-30 years ago (when the convention was to begin with some positive points before going on to the weaknesses and problems). Others are becoming more transactional in their behaviour, asking 'What's in it for me?' and only agreeing to undertake things for which there are 'brownie points' (i.e. things that 'count' on their CV). An increasing proportion seem unwilling to contribute to 'public goods', for example providing reviews of papers for journals or of proposals for funding agencies. In some cases, individuals are also becoming more secretive, reluctant or unwilling to share ideas with others for fear of being 'scooped' to publication and thereby losing credit for that idea.

Thus the challenge posed here is that of:

- Maintaining our sense of collegiality, social responsibility and civility

\subsection{Impact on research behaviour - misconduct and questionable research practices}

As journal editors know to their cost, the academic world is experiencing a rapidly growing level of research misconduct (conventionally defined in terms of data 
fabrication, data falsification and plagiarism ${ }^{22}$ ). Evidence for this comes, for example, from the ten-fold increase in the number of retractions made by journals over a single decade (Van Noorden, 2011). SPIS has unfortunately not been immune from this trend. Ten years ago, it was revealed that Hans Werner Gottinger had engaged in serial plagiarism over most of his academic career (Abbott, 2007; Martin et al., 2007). More recently, papers by Ulrich Lichtenthaler were found to contain data falsification (with exaggerated p-values) as well as deliberately omitted variables, as a result of which 16 of his journal articles have since been retracted. ${ }^{23}$

The task of policing research misconduct inevitably falls primarily on journal editors, now taking up a significant and growing proportion of their time. However, even more effort is devoted to addressing not outright misconduct but more questionable research practices, where the rules of behaviour are less clear or not universally agreed (Hall and Martin, 2017). Examples here include salami publishing, parallel or redundant publications, and self-plagiarism. Another increasingly common problem is that of HARKing (hypothesising after the results are known - see Kerr, 1998). This is partly driven by a desire to get published in top journals, for which one generally needs clear and statistically significant results, bringing with it the temptation to exaggerate or otherwise manipulate the data in order to achieve this. However, it is also driven by the mechanism supposedly aiming to provide quality control - i.e. peer review - with referees often noting that a particular hypothesis has not been confirmed at the $1 \%$ or

\footnotetext{
22 See e.g. http://grants.nih.gov/grants/research_integrity/research_misconduct.htm (accessed on 29 November 2017).

23 See Retraction Watch (http://retractionwatch.com/2014/10/10/after-16-retractions-management-professor-lichtenthaler-resigns-
} post/ - accessed on 29 November 2017). 
5\% level, and suggesting that the author try another hypothesis instead in their revised version of the paper (ibid.).

The problem with such questionable research practices is that there are generally no clear or mutually agreed rules or boundaries with regard to what constitutes appropriate research behaviour and what does not (see Hall and Martin, 2017). Hence, some researchers under particular pressure to deliver (e.g. a published journal article or a conference presentation by a given deadline) may be tempted to 'push the boundary' or otherwise cut corners. This may be encouraged by the wider moral climate of recent years, in which there is often an implicit belief that all that is not forbidden is fair game to be exploited for individual or organisational gain. When challenged, the accused tend to hide behind the excuse that what they have done is not explicitly proscribed, therefore they have done nothing wrong. This represents an abrogation of any sense of individual (or organisational) morality - in other words, working out in a specific situation whether particular behaviour is or is not what most reasonable people would regard as acceptable, ethical and moral.

Such dubious or unprincipled behaviour has been witnessed especially in the business and financial sectors, where those prepared to push the boundaries furthest often end up with immense wealth. However, it has also spread to other professions, including academic researchers. In recent years, a number of prominent scientists and social scientists have either been found guilty of misconduct (e.g. Hauser, Hwang, Förster, Macchiarini, Schön, Stapel) or at least had their behaviour called into question (e.g. Frey, Nijkamp).

Hence, the final challenge to be put forward here is: 


\section{- Maintaining our research integrity}

\section{Conclusions}

In previous papers (Martin, 2013; 2016), following the example of Hilbert and the 23 mathematical problems that he set for future generations of mathematicians, I attempted to identify some emerging challenges facing the field of science policy and innovation studies. Perhaps the challenges identified may have appeared to some as relatively subjective, overly reflecting my own experiences (40 years of research at SPRU and a dozen years as Editor of Research Policy). In this chapter, I have attempted to set those challenges in a clearer analytical framework. In particular, I have sought to identify the main factors underlying those challenges. My intention is to understand those underlying factors, and hence to enable SPIS researchers to be better placed to take on and eventually overcome these challenges.

Almost inevitably, the list of specific challenges that emerges from this broader analysis is not identical with those in my two previous publications on the subject. In particular, because I have included here underlying factors that are not specific to SPIS but more generic to the academic research world, some of the challenges are rather broader in nature. Nevertheless, the very considerable overlap between the list of challenges set out here and those in the two earlier publications suggests that those earlier attempts to synthesise the main challenges were not entirely subjective or arbitrary.

From the analysis set out above, we have arrived at the following list of challenges summarised in Table 1 below. 
Table 1. Eighteen challenges for science policy and innovation studies

\begin{tabular}{|c|l|}
\hline 1 & From innovation in manufacturing to innovation in services \\
\hline 2 & $\begin{array}{l}\text { From innovation for productivity to innovation for sustainability ('green } \\
\text { innovation') }\end{array}$ \\
\hline 3 & $\begin{array}{l}\text { From innovation for economic growth to innovation for sustainable } \\
\text { development }\end{array}$ \\
\hline 4 & From innovation for wealth creation to innovation for well-being \\
\hline 5 & From risky innovation to socially responsible innovation \\
\hline 6 & $\begin{array}{l}\text { From innovations based on 'winner take all' to innovations generating 'fairness } \\
\text { for all' }\end{array}$ \\
\hline 7 & From visible innovation to 'dark innovation' \\
\hline 8 & $\begin{array}{l}\text { From 'boy's toys' to often more mundane innovations that have done (or could } \\
\text { potentially do) at least as much to improve the lot of humanity }\end{array}$ \\
\hline 9 & Avoiding disciplinary sclerosis \\
\hline 10 & Encouraging risk-taking and diversity \\
\hline 11 & $\begin{array}{l}\text { Developing customised databases specific to the key factors at work (rather } \\
\text { than re-using data that happen to be already available) }\end{array}$ \\
\hline 12 & Pricking academic bubbles and moving beyond today's fads \\
\hline 13 & Breaking free from the tyranny of performance indicators \\
\hline 14 & $\begin{array}{l}\text { Rejecting the assumption that one can judge the importance of a publication by } \\
\text { the status of the journal in which it appeared }\end{array}$ \\
\hline 15 & Contributing to efforts to expose and exclude predatory publishers \\
\hline 16 & $\begin{array}{l}\text { Establishing reputable open-access journals for the social sciences } \\
\text { Maintaining our sense of collegiality, social responsibility and civility }\end{array}$ \\
\hline 18 & Maintaining our research integrity \\
\hline 17 & \\
\hline 12
\end{tabular}

In summary, we have seen how in the light various underlying factors, the field of science policy and innovation studies is confronted by a number of emerging challenges. In particular, the focus of our empirical studies has not always kept pace with a rapidly changing world and economy, especially the transition from manufacturing to services and the growing priority on sustainability rather than economic growth. Moreover, the 
very way we conceptualise, define, operationalise and analyse 'innovation' may be too heavily rooted in the past, leaving us poorly positioned to grapple with other less visible or 'dark' forms of innovation occurring today. For example, the relative neglect of financial innovations ${ }^{24}$ has left us with little to contribute to the analysis of the recent financial crisis, and how economics needs to be fundamentally restructured or even shifted to a new paradigm if we are to avoid similar problems in the future. ${ }^{25}$

Let me conclude by emphasizing that the list of challenges presented here is not intended to be prescriptive. My purpose is to join with others in a debate on these matters. Such a debate may help shape the future of science policy and innovation studies over coming decades.

\section{Acknowledgements}

This chapter draws upon a paper originally prepared for the Lundvall symposium in 2012, later published as a chapter in a book based on the proceedings of that symposium (Martin, 2013). A longer and more detailed version of that paper identifying 20 challenges was subsequently published as a journal article (Martin, 2016b). During the preparation of the latter, I was encouraged by my SPRU colleague, Paul Nightingale, to focus on identifying the factors underlying the challenges I had identified in the previous two papers. I am grateful to him as well as to all those who contributed to the two earlier papers. Very useful comments on a preliminary draft of this chapter were

\footnotetext{
24 Our neighbours in STS (science and technology studies) have had at least as much to say here - see e.g. MacKenzie (2012) and MacKenzie and Spears (2014). For a discussion of the evolving relationship between the fields of STS and SPIS, see Williams (this volume).

25 This and the final paragraph draw on the concluding section of Martin (2013).
} 
provided by Jochen Gläser, Benoït Godin, Stefan Kuhlmann and Richard Whitley. Responsibility for any remaining errors lies with the author.

\section{References}

Abbott, A. (2007), ‘Academic accused of living on borrowed lines’, Nature, 448, 632-633.

Abrahamson, E. (1996), ‘Management fashion', Academy of Management Review, 21, 254-285.

Attema, A.E., W.B.F. Brouwer and J. van Exel (2014), 'Your right arm for a publication in AER?', Economic Inquiry, 52, 495-502.

Autor, D., D. Dorn, L.F. Katz, C. Patterson and J. Van Reenen (2017), 'The fall of the labor share and the rise of superstar firms’, IZA Discussion Paper 10756 (downloaded from ftp://repec.iza.org/RePEc/Discussionpaper/dp10756.pdf on 29 November 2017).

Barras, R. (1986), 'Towards a theory of innovation in services', Research Policy, 15, 161-173.

Barras, R. (1990), 'Interactive innovation in financial and business services: the vanguard of the service revolution', Research Policy, 19, 215-237.

Bernhofen, D.M., Z. El-Sahli and R. Kneller (2016), 'Estimating the effects of the container revolution on world trade', Journal of International Economics, 98, 36-50.

Bijker, W.E., T.P. Hughes and T.J. Pinch (eds) (1987), The Social Construction of Technological Systems: New Directions in the Sociology and History of Technology, Cambridge, Mass.: MIT Press. 
Coase, R. (2012), 'Saving economics from the economists', Harvard Business Review, 90 (12), 36.

Diesing, P. (1982/2005), Science and Ideology in the Policy Sciences (2nd edition), Brunswick, New Jersey: Transaction Publishers.

Fagerberg, J., E.S. Andersen and B.R. Martin (eds) (2013), The Future of Innovation Studies, Oxford: Oxford University Press.

Fagerberg, J. and B. Verspagen (2009) 'Innovation studies: the emerging structure of a new scientific field', Research Policy, 38, 218-33

Freeman, C. (1995), 'The 'national system of innovation' in historical perspective’, Cambridge Journal of Economics, 19, 5-24

Frank, R.H. and P.L. Cook (1995), The Winner-Take-All Society: Why the Few at the Top Get so Much More than the Rest of Us, New York: Free Press.

Gershuny, J. and J.P. Robinson (1988), 'Historical changes in the household division of labour', Demography, 25, 537-552.

Godin, B. (this volume), 'Innovation and the marginalization of research', Chapter ?? in this volume.

Hall, J. and B.R. Martin (2017), 'Towards a taxonomy of academic misconduct: the case of business school research', submitted to Research Policy.

Hartmann, H.I. (1981), 'The family as the locus of gender, class and political struggle: the example of housework', Signs, 6, 366-394.

Hellström, T. (2003), 'Systemic innovation and risk: technology assessment and the challenge of responsible innovation', Technology in Society, 25, 369-384. 
Hicks, D., P. Wouters, L. Waltman, S. de Rijcke and I. Rafols (2015), ‘The Leiden Manifesto for research metrics’, Nature, 520, 429-431.

Huczynski, A.A. (1993), 'Explaining the succession of management fads’, The International Journal of Human Resource Management, 4, 443-463

Kan, M.Y., O. Sullivan and J. Gershuny (2011), 'Gender convergence in domestic work', Sociology, 45, 234-251.

Kerr, N.L. (1998), ‘HARKing: hypothesizing after the results are known’, Personality and Social Psychology Review, 2, 196-217.

Kim, E.H., A. Morse and L. Zingales (2006), 'What has mattered to economics since 1970?', Journal of Economic Perspectives, 20, 189-202.

Kolata, G. (2017), 'Many academics are eager to publish in worthless journals’, New York Times, 30 October 2017 (downloaded on 29 November 2017 from https://www.nytimes.com/2017/10/30/science/predatory-journals-academics.html ). Krugman, P. (2009), 'How did economists get it so wrong?', New York Times (6 September, p.MM36) (accessed at http://www.nytimes.com/2009/09/06/magazine/06Economic-t.html?pagewanted=all\&_r $\underline{=0}$ on 29 November 2017).

Lawson, T. (2009), 'The current economic crisis: its nature and the course of academic economics', Cambridge Journal of Economics, 33, 759-777.

Lindsay, J. and P. Boyle (2017), 'The conceptual penis as a social construct', Cogent Social Sciences, 3, 1330439 (subsequently withdrawn but available from https://web.archive.org/web/20170520194758/https://www.cogentoa.com/article/10.108 0/23311886.2017.1330439.pdf - accessed 29 November 2017). 
Lundvall, B.-Å (2004), 'Introduction to 'Technological infrastructure and international competitiveness’ by Christopher Freeman’, Industrial and Corporate Change, 13, 531-539.

Maasen, S. and S. Dickel (this volume), 'Normative answers - epistemic questions: updating the science-society contract', Chapter ?? in this volume.

MacKenzie, D. (2012), ‘Knowledge production in financial markets: credit default swaps, the ABX and the subprime crisis', Economy and Society, 41, 335-359.

MacKenzie, D. and T. Spears (2014), “ “The formula that killed Wall Street”: the Gaussian copula and modelling practices in investment banking', Social Studies of Science, 44, 393-417.

Mackenzie, D. and J. Wajcman (eds) (1985), The Social Shaping of Technology, Milton Keynes: Open University Press.

Marsili, O. and A. Salter (2006), 'The dark matter of innovation: design and innovative performance in Dutch manufacturing', Technology Analysis \& Strategic Management, $18,515-534$.

Martin, B.R. et al. (2007), 'Keeping plagiarism at bay - a salutary tale’, Research Policy, 36, 905-911.

Martin, B.R. (2012), 'The evolution of science policy and innovation studies’, Research Policy, 41, 1219-1239.

Martin, B.R. (2013), 'Innovation studies: an emerging agenda’, in Fagerberg et al (2013), pp.168-186.

Martin, B.R. (2016a), ‘Editors’ JIF-boosting stratagems - which are legitimate and which not?’, Research Policy, 45, 1-7. 
Martin, B.R. (2016b), ‘Twenty challenges for innovation studies’, Science and Public Policy, 43, 432-450.

Nelson, R.R. (2016), ‘The sciences are different and the differences matter’, Research Policy, 45, 1692-1701.

NESTA (2006), The Innovation Gap: Why Policy Needs to Reflect the Reality of Innovation in the UK, London: NESTA.

NESTA (2007), Hidden Innovation: How Innovation Happens in Six 'Low Innovation' Sectors, London: NESTA.

Owen, R. and N. Goldberg (2010), 'Responsible innovation: a pilot study with the U.K. Engineering and Physical Sciences Research Council', Risk Analysis, 30, 1699-1707.

Owen, R. and M. Pansera (this volume), 'Responsible innovation and responsible research and innovation', Chapter?? in this volume.

Perez, C. (2013), 'Innovation systems and policy: not only for the rich?', in Fagerberg et al. (2013), pp.90-110.

Romer, P. (2015), 'Mathiness in the theory of economic growth', American Economic Review: Papers \& Proceedings 2015, 105 (5), 89-93.

Schein, E.H. (1983), 'The role of the founder in creating organizational culture', Organizational Dynamics, 12, 13-28.

Schilling, M.A. (2002), 'Technology success and failure in winner-take-all markets: the impact of learning orientation, timing, and network externalities', Academy of Management Journal, 45, 387-398.

Schot, J. and W.E. Steinmueller (2016), ‘ Framing innovation policy for transformative change: innovation policy 3.0’, SPRU Working Paper, Science Policy Research Unit, 
University of Sussex (downloaded on 29 November 2017 from

http://www.johanschot.com/wordpress/wp-content/uploads/2016/09/SchotSteinmueller_ FramingsWorkingPaperVersionUpdated2018.10.16-New-copy.pdf ).

Simon, D. and A. Knie (2013), 'Can evaluation contribute to the organizational development of academic institutions? An international comparison', Evaluation, 19, 402-418.

Smolin, L. (2006), The Trouble with Physics, Boston, MA: Houghton Mifflin.

Steinmueller, W.E. (2013), 'Innovation studies at maturity’, in Fagerberg et al. (2013), pp.147-167.

Stinchcombe, A.L. (1965), 'Social structure and organizations’, in J.G. March (ed.), Handbook of Organizations, Chicago: Rand McNally, pp.142-193.

Teece, D.J. (forthcoming), 'Profiting from innovation in the digital economy: standards, complementary assets, and business models in the wireless world', Research Policy (a Discussion Paper due to be published in 2018).

Tickell, A. (2000), 'Dangerous derivatives: controlling and creating risks in international money’, Geoforum, 31, 87-99.

Tourish, D. (2011), 'Leading questions: journal rankings, academic freedom and performativity: what is, or should be, the future of leadership?', Leadership, 7, 367-381. Van Noorden, R. (2011), 'Science publishing: the trouble with retractions', Nature, 478, 26-28.

von Schomberg, R. (ed.), Towards Responsible Research and Innovation in the Information and Communication Technologies and Security Technologies Field, Luxembourg: European Commission. 
Whitley, R.D. (this volume), 'Changing science policies, authority relationships and innovations in pubic science systems, Chapter ?? in this volume.

Williams, R. (this volume), 'Why science and innovation policy needs Science and Technology Studies', Chapter ?? in this volume.

Williams, R. and D. Edge (1996), 'The social shaping of technology’, Research Policy, 25, 865-899.

\section{Short bio of the author:}

Ben Martin is Professor of Science and Technology Policy Studies at SPRU, where he served as Director from 1997 to 2004. He is also an Associate Fellow at the Centre for Science and Policy (CSaP), and a Research Associate at the Centre for Business Research, Judge Business School, both at the University of Cambridge. He has carried out research for 40 years in the field of science policy. He helped to establish techniques for evaluating scientific laboratories, research programmes and national scientific performance. He also pioneered the notion of 'technology foresight'. More recently, he has carried out research on the benefits from government funding of basic research, the changing nature and role of the university, the impact of the Research Assessment Exercise, and the evolution of the field of science policy and innovation studies. He has also published several papers on research misconduct. Since 2004, he has been Editor of Research Policy, and he is also the 1997 winner of the de Solla Price Medal for Science Studies. 